\title{
Promoting evidence-based practice: training health professionals for the evidence synthesis
}

\author{
Promoção da prática baseada em evidências: formação de profissionais de saúde para a \\ síntese da evidência \\ Promoción de la práctica basada en la evidencia: formación de profesionales de salud para la \\ síntesis de la evidencia
}

How to cite this article:

Cardoso DFB, Santos DGSM, Rodrigues JFC, Bento N, Rodrigues RMC, Cardoso AFRM. Promoting evidence-based practice: training health professionals for the evidence synthesis. Rev Esc Enferm USP. 2021;55:e20210180. https://doi.org/10.1590/1980-220X-REEUSP-2021-0180.

\section{Daniela Filipa Batista Cardoso ${ }^{1}$ \\ iD Diana Gabriela Simões Marques Santos ${ }^{1}$ \\ (iD) Joana Filipa Cunha Rodrigues ${ }^{1}$ \\ D Nichole Bento ${ }^{1}$ \\ Rogério Manuel Clemente Rodrigues ${ }^{1}$ \\ (iD) Ana Filipa dos Reis Marques Cardoso ${ }^{1}$}

${ }^{1}$ Centro Português para a Prática Baseada na Evidência: um Centro de Excelência JBI, Unidade de Investigação em Ciências da Saúde: Enfermagem, Escola de Enfermagem de Coimbra, Coimbra, Portugal.

\begin{abstract}
Objective: To report the experience of the Portugal Centre For Evidence Based Practice (PCEBP): a JBI Centre of Excellence in the training of health professionals, researchers, and professors in the Comprehensive Systematic Review Training Program, a course on Evidence Synthesis, specifically on Systematic Literature Reviews. Method: This article aims to report the experience of the Portugal Centre For Evidence Based Practice: a JBI Centre of Excellence in the implementation of the Comprehensive Systematic Review Training Program that trains health professionals, researchers, and teachers to develop Systematic Reviews, according to the JBI approach. Results: By the end of 2020,11 editions of the course had been developed with 136 participants from different educational and health institutions, from different countries. As a result of the training of these participants, 13 systematic reviews were published in JBI Evidence Synthesis and 10 reviews were published in other journals. Conclusion: The reported results and the students' satisfaction evaluation allow us to emphasize the relevance of the course for health professionals training on evidence synthesis.
\end{abstract}

\section{DESCRIPTORS}

Evidence-Based Practice; Health Personnel; Delivery of Health Care; Systematic Review; Professional Training. 


\section{INTRODUCTION}

The Evidence-Based Practice (EBP) movement, strongly driven since the 1990s, alerted to the need for health professionals to make clinical decisions informed by the best available evidence, while considering their clinical experience as a professional, the beliefs, values, and concerns of people, and the context where care is provided ${ }^{(1-3)}$.

In fact, the use of EBP in the context of clinical practice allows to improve health outcomes, people's experiences, as well as to reduce health $\operatorname{costs}^{(4,5)}$.

This awareness, which has taken place more intensely in the last 25 to 30 years, derives from several factors, such as: the enormous production of primary studies; the gap between knowledge generation and its incorporation into clinical practice; the quality and safety of healthcare; and the pressure of citizens who have increasingly faster access to scientific knowledge produced in the health area ${ }^{(6,7)}$.

However, the implementation of EBP is still a challenge, due to the existing barriers, such as the lack of time and work overload, the organizational culture, the deficit in knowledge about EBP, the lack of access and knowledge in the use of scientific databases, resistance from leaders and clinicians, and the lack of EBP mentors. The presence of these barriers reduces the provision of health care informed by the best available evidence, which consequently leads to a negative impact on health outcomes, on costs associated with health care, and on the experience of the person being cared for ${ }^{(4)}$.

In an attempt to respond to this challenge, over the last decades, several conceptual models were built with the purpose of guiding the process of EBP implementation and its sustainability in healthcare. Some examples are: the Advancing Research and Clinical Practice through Close Collaboration (ARCC@) Model; the Promoting Action on Research Implementation in Health Services (PARIHS) Model, or the Joanna Briggs Institute (JBI) Model of Evidence-Based Healthcare ${ }^{(5,8)}$.

The development of this article is guided by the JBI Model of Evidence-Based Healthcare. Based on the JBI perspective, EBP is defined as the clinical decision that considers reliability, adequacy, significance, and effectiveness of health practices. The JBI Model of Evidence-Based Healthcare is based on four principles: culture, capacity, communication, and collaboration. These reflect the clinical practice reality, as the clinical context is a multifaceted environment that, consequently, influences the process of incorporating scientific evidence into practice ${ }^{(5)}$.

According to the aforementioned model, evidence-based health care represents a cyclical process that fluctuates between questions and concerns about a particular phenomenon of interest to health professionals or citizens, which then become issues that generate knowledge and scientific evidence to effectively and adequately meet the identified needs ${ }^{(3)}$. According to the graphical representation of this model, the internal segments respond to the cyclical process described above, symbolizing the steps of an evidence-based approach to clinical decision making: Global Health, Evidence Generation, Evidence Synthesis, Evidence Transfer, and Evidence Implementation ${ }^{(5)}$.

In the Global Health component, sustainable impact, involvement, and the need for knowledge are integrated. In the context of this model, Global Health is defined as collaborative translational research and action that prioritizes health improvement and equity achievement for all people globally, so it is the component that serves both as a starting (goal) and arrival (final result) point ${ }^{(5)}$.

Regarding Evidence Generation, it represents properly conceived research, which is based on any methodology, opinion, or experience. The JBI model proposes that evidence can emerge from different sources, with research, experiences, and discourse being the three integral parts of this component ${ }^{(5)}$.

The segment called Evidence Synthesis represents the assessment and analysis of evidence from scientific research and opinions, on a specific theme, guiding decision-making in healthcare. It consists of three segments: Systematic Literature Revierws (SLR), Evidence Summaries and Guidelines ${ }^{(5)}$. In fact, scientific knowledge from primary studies has increased considerably in recent decades, making it impossible for health professionals to be constantly updated with the scientific evidence generated and published in a given are $\mathrm{a}^{(9)}$. For example, according to Summary Indexing Statistics: 1965-2017 of MEDLINE ${ }^{(10)}$, the total number of references indexed in MEDLINE grew significantly, from 10,796,185 in 2000 to $24,335,332$ in 2017. The SLR thus arise with the objective of synthesizing and summarizing the existing knowledge about a phenomenon of specific interest by providing a comprehensive and impartial synthesis of several relevant primary studies, in a single document, through the use of rigorous and transparent methods ${ }^{(11)}$. According to JBI, there are several types of SLR, such as: experience or meaning; of effectiveness; text and opinion; of prevalence and incidence; of costs associated with a particular intervention, process, or procedure; of etiology and risk; of mixed methods; diagnostic test accuracy; and of reviews (umbrella) ${ }^{(11)}$. In addition to the SLR, JBI also reports a methodology for Scoping Reviews, which, despite not being considered an SLR methodology, has to follow a rigorous and systematic process ${ }^{(11)}$. At the same time, Evidence Summaries emerged with the objective of succinctly synthesizing the information generated, allowing the obtainment of scientific information synthesized by health professionals and citizens in a reduced period of time. In their turn, the Guidelines include recommendations for clinical practice, built not only from systematic reviews, but also considering the evaluation of the benefits of the proposed options through scientific evidence ${ }^{(5,12)}$.

Following Evidence Synthesis, there is the Evidence Transfer component. Here the processes promoting access to evidence are considered and, consequently, its use in clinical practice contexts through dissemination, integration in systems (use of computer systems to support clinical decision), and education ${ }^{(5)}$.

Finally, the cycle of the model proposed by JBI presents the Evidence Implementation component, which includes context analysis, the facilitation of practice change, and process and results assessment $t^{(5,11)}$.

Given the importance that evidence synthesis assumes throughout the process of translation of evidence into clinical practice, exemplified above through the JBI Model of Evidence-Based Healthcare, we intend, in this article, to report on the experience of the Portugal Centre For Evidence Based Practice (PCEBP): a JBI Centre of Excellence in training health 
professionals, researchers, and professors in the Comprehensive Systematic Review Training Program, a course in Evidence Synthesis, specifically about Systematic Literature Reviews.

\section{METHOD}

This is an experience report of a JBI Centre, currently a Centre of Excellence, on the training of health professionals, researchers, and professors in systematic reviews, through the Comprehensive Systematic Review Training Program.

\section{JBI: Organization and Activities}

JBI is an international, independent, non-profit research and innovation organization. It was founded by Professor Alan Pearson in 1996 and until 2010 was headquartered at the Royal Adelaide Hospital in South Australia. In 2010, its headquarters moved to the University of Adelaide, in South Australia ${ }^{(13)}$. Currently, JBI's vision is to promote better health outcomes, contribute to a brighter future, and use the best evidence in health care. This organization has as primary focus to improve health outcomes around the world, through the promotion of informed decision-making by the best evidence available. With this objective, JBI ensures that the scientific evidence that it seeks to synthesize, transfer, and implement is culturally inclusive and relevant to the international healthcare diversity. Accordingly, they defend the importance and inclusion of evidence in the clinical decision-making process not only of effectiveness, but also of reliability, adequacy, and meaning.

JBI cooperates with collaborating entities around the world, through the dissemination of knowledge, the promotion of training activities, and the implementation of evidence in clinical practice. This organization recognizes its collaborating entities as JBI Centers of Excellence and JBI Affiliate Groups ${ }^{(14)}$.

JBI Centers of Excellence are characterized as a prestigious center of expertise, through which high quality evidence synthesis, transfer, and implementation programs are achieved. These are recognized by JBI as an entity that provides leadership, support, and guidance to newer groups and meet the required competencies and key performance indicators as defined by JBI. These centers are also eligible to receive JBI funding for their activities, including the Center Director's participation in the annual meeting. JBI Affiliate Groups are committed to promoting and supporting the synthesis, transfer, and implementation of evidence. These collaborating entities are not eligible to receive JBI funding, but are supported with access to resources and are welcome and encouraged to attend the annual general meeting of the JBI Collaboration (JBIC). All JBI Affiliate Groups have the opportunity to become JBI Centers of Excellence if they achieve the necessary competencies and meet the key development indicators after 12 months as established by JBI. These centers are distributed all over the world, covering more than 70 collaborating entities in about 39 countries $^{(14)}$.

\section{Portugal Centre for Evidence-Based Practice}

The Portugal Centre For Evidence-Based Practice (PCEBP) is a collaborating entity of JBI. The initiative came about in 2009 with a meeting with JBI's Executive Director, and in July of that same year the application process for the establishment of a JBI Affiliate Center in Portugal began. First, six researchers from the Health Sciences Research Unit:Nursing (UICISA:E) of the Escola Superior de Enfermagem de Coimbra held the Comprehensive Systematic Review Training Course at the Universidade de Thames Valley, mandatory criteria for formalizing the application. After submitting the application in 2010, UCISA:E became a JBI Affiliate Center in 2011 and, since 2016, it has been recognized as a JBI Center of Excellence.

Currently, the team consists of a Director, an Associate Director, 10 core staff members, and 11 adjunct staff members.

According to the original Cross-Cutting Model for the management of Research and Development activities in the field of nursing at UICISA:E, the PCEBP is a resource of the Development Strategic Axis (EED) for the Synthesis and Implementation of Science in that Research Unit located at the Escola de Enfermagem de Coimbra (ESEnfC).

This strategic axis has the mission of developing EBR, acting in the international network of JBI collaborating centers for the synthesis and implementation of science. To achieve its mission, the $E E D$ for Synthesis and Implementation aims at producing SLR according to the JBI approach, promoting the implementation of evidence in clinical practice, training activities within the scope of the synthesis and implementation of science, as well as disseminating JBI activities ${ }^{(15)}$.

In this context, PCEBP has invested heavily in the training of health professionals, researchers, and professors in the area of science synthesis, namely in the Comprehensive Systematic Review Training Program (CSRTP) course, which we present below.

\section{RESULTS}

\section{PCEBP EXPERIENCE IN THE IMPLEMENTATION OF THE Comprehiensive Systematic Review Training Program}

CSRTP allows participants to understand and use systematic reviews to promote evidence-based health care, as well as empower participants to produce systematic reviews through the JBI approach. Participants will be able to use JBI's SLR development support software - the JBI System for Unified Management, Assessment and Review of Information (JBI SUMARI)(16).

It is an in-person, 5-day course that consists of three modules. Module 1 is called Introduction to Evidence-Based Health Care and to the Systematic Literature Review (day 1); Module 2, The Systematic Review of Quantitative Evidence (days 2 and 3); and Module 3, The Systematic Review of Qualitative, Narrative and Text Evidence (days 4 and 5) ${ }^{(16)}$.

With respect to Module 1, the aim is to understand the principles and assumptions of evidence-based healthcare. This module presents the steps in the process of developing a systematic review: (1) formulation of the review question(s) and objective(s); (2) definition of inclusion and exclusion criteria; (3) development of the research strategy to identify the studies; (4) selection of studies; (5) assessment of the methodological quality of eligible studies; (6) data extraction; (7) data synthesis; (8) presentation of results; and (9) interpretation of results ${ }^{(16,17)}$. However, in this module, special emphasis is given to the first four steps that are common to all types of SLR. 
Module 2 focuses on the synthesis of quantitative evidence. Thus, contents about effectiveness, prevalence and incidence SLR, and etiology and risk are addressed, including the designs of quantitative studies, the tools for their critical evaluation, the extraction and synthesis of quantitative data (meta-analysis), the principles involved in the interpretation of the results, and the determination of evidence confidence/certainty ${ }^{(16)}$.

Module 3 is similar to the previous one; however, with a focus on qualitative evidence. In this module, the different methodologies of qualitative review are addressed, including the process of evaluating the methodological quality of qualitative studies, and the extraction of data and synthesis of information from qualitative evidence and opinion text (meta-aggregation) ${ }^{(16)}$.

There are no prerequisites to attend the program; however, there is a maximum limit of 14 participants (criterion implemented by the PCEBP and according to JBI guidelines), to allow for discussion in small groups and to promote interaction between the trainer(s) and the participants. Participants are selected considering the order of enrollment in the training. It should be noted that, in order to complete Module 2 and 3, participants have to complete Module 1 successfully.

For CSRTP to be taught by the PCEBP, the training of members of its Core Staff in the Comprehensive Systematic Review Program train-the-trainer (CSRTP-TtT) was required. This course is provided by JBI for the certification of trainers in this area. The first member conducted this training in 2013, the second in 2016 and the third in 2018. Therefore, PCEBP has been carrying CSRTP out since 2014 at least once a year. However, at the request of institutions or by demonstration of interest from the target audience, in some years 2 or 3 editions are held. By the end of 2020, PCEBP had organized 11 editions for a total of 136 participants (health professionals, researchers, and professors in the fields of nursing, medicine, and psychology) from different educational and health institutions, from different countries, such as Portugal, Spain, Brazil, Costa Rica (Table 1).

In 2014, the first edition was held at UICISA:E from ESEnfC, with 12 participants, from different health and educational institutions in Portugal, e.g. the Centro Hospitalar e Universitário de Coimbra ( $C H U C)$, the Centro Hospitalar Universitário do Porto (CHUP), Escola Superior de Enfermagem de Coimbra (ESEnfC), Escola Superior de Enfermagem do Porto $(E S E P)$, Escola Superior de Enfermagem de Lisboa (ESEL), Universidade de Aveiro, Universidade de Évora, Escola Superior de Saúde - Instituto Politécnico de Santarém (ESS$I P S)$, and Escola Superior de Saúde do Politécnico de Leiria (ESSLEI). In this edition, the course was taught by the PCEBP Core Staff trainer and by an external certified trainer (from the United Kingdom).

In 2015, the second edition also took place at UICISA:E with seven participants, from Portugal, Spain, and Brazil, from the following institutions: $E S E n f C$, Universidade Católica Portuguesa $(U C P)$ - Porto, Escola de Enfermagem de Ribeirão Preto da Universidade de São Paulo (EERP-USP), and Universidad de Lleida.

The next edition took place in 2016 and had 10 participants from various institutions in Portugal and Brazil: $C H U C$, Centro Hospitalar Universitário de São João (CHUSJ), Centro Hospitalar Universitário do Algarve $(C H U A)$ - Hospital de Faro, Faculdade de Psicologia e de Ciências da Educação Universidade do Porto, UCP - Lisboa, EERP-USP, Universidade Federal de Viçosa, and Escola Superior de Educação João de Deus.

In 2017, three editions were held: one at the School of Nursing at the University of Costa Rica, San José (five participants); one at UICISA:E (14 participants), and one at ESEL (11 participants). Participants came from the respective institutions, except for the session held at UICISA:E, which included trainees not only from $E S E n f C$, but also from CHUSJ, Hospital Professor Doutor Fernando Fonseca, Hospital Garcia da Orta (HGO), UCP - Lisbon, ESEP, and ESSLEI.

The seventh edition was held in 2018 at UICISA:E, with 14 participants from Portugal and Brazil, from the following institutions: $C H U A, U C P$-Porto and Lisbon, CHUSJ, Unidade de Cuidados de Saúde Personalizados da Praça da República, $H G O$, Centro Hospitalar Psiquiátrico Lisboa, CHUC, and ESEnfC.

In 2018, the eighth and ninth editions took place at UICISA:E with 12 and 13 participants, respectively. The trainees were from $C H U C$, Centro Hospitalar Tondela-Viseu, Hospital Curry Cabral - Lisbon, Instituto Português de Oncologia de Coimbra, UCP-Lisbon, Universidade Federal São João del-Rei, Universidade de Évora, Universidade de Aveiro, Escola Superior

Table 1 - Description of the editions of the Comprehensive Systematic Review Training Program - Coimbra, Portugal, 2021.

\begin{tabular}{ccccc}
\hline CSRTP & Date of event & Place of event & Number of participants & Origin \\
\hline $1^{\text {st }}$ CSRTP & June 2014 & UICISA:E/ESEnfC & 12 & Portugal \\
$2^{\text {nd }}$ CSRTP & July 2015 & UICISA:E/ESEnfC & 7 & Portugal, Spain, and Brazil \\
$3^{\text {rd }}$ CSRTP & May/June 2016 & UICISA:E/ESEnfC & 10 & Portugal and Brazil \\
$4^{\text {th }}$ CSRTP & February 2017 & Escola de Enfermagem da Universidade da Costa Rica, San José & 5 & Costa Rica \\
$5^{\text {th }}$ CSRTP & June 2017 & UICISA:E/ESEnfC & 14 & Portugal and Brazil \\
$6^{\text {th }}$ CSRTP & July 2017 & Escola Superior de Enfermagem de Lisboa & 11 & Portugal \\
$7^{\text {th }}$ CSRTP & June 2018 & UICISA:E/ESEnfC & 14 & Portugal and Brazil \\
$8^{\text {th }}$ CSRTP & January 2019 & UICISA:E/ESEnfC & 12 & Portugal and Brazil \\
$9^{\text {th }}$ CSRTP & June 2019 & UICISA:E/ESEnfC & 13 & Portugal \\
$10^{\text {th }}$ CSRTP & February 2020 & UICISA:E/ESEnfC & 14 & 14 \\
$11^{\text {th }}$ CSRTP & November 2020 & UICISA:E/ESEnfC & 14 & Portugal \\
\hline
\end{tabular}


de Saúde - Instituto Politécnico da Guarda, ESEnfC, ESEL, and Escola Superior de Enfermagem da Universidade do Minho.

At the beginning of 2020, in the tenth edition, also developed at UICISA:E, 14 trainees from different institutions participated: Agrupamento de Centros de Saúde do Dão Lafões, Diaverum - Unidade da Figueira da Foz, Hospital Santa Cruz Centro Hospitalar Lisboa Ocidental, CHUC, CHUSJ, Escola Superior de Saúde Viseu - Instituto Politécnico de Viseu, ESEP, $U C P$, and ESEnfC.

Due to the pandemic situation by COVID-19, the $11^{\text {th }}$ edition took place in online format in the second half of 2020, through the Zoom platform. This edition was attended by 14 participants from educational institutions only: $E S E n f C, E S E P$, $U C P$-Porto, Universidade de Évora, Faculdade de Medicina da Universidade de Coimbra, Escola Superior de Saúde de Viana do Castelo, and Escola Superior de Saúde Egas Moniz.

Feedback from participants about the Course throughout the different editions is, in general, very positive. Several participants reported that the course is very useful and that the approach to the content, which is pertinent in itself, is interesting and motivating. They also reported that the team of trainers has clear skills in the area and promotes the students' motivation, being always available to clarify questions/doubts. However, participants report that the course is very intense, given the density of the contents. They presented, as a suggestion, the development of the course for a longer time, to allow room for discussion and reflection by and among the participants.

Parallel to the formal courses offered by PCEBP, the center, through its more experienced staff, offers guidance to researchers from other institutions intending to conduct systematic reviews following the methodologies proposed by the JBI. This way, it promotes not only cooperative work among researchers with different backgrounds and know-how, but also the training of new researchers in the area of evidence synthesis.

Therefore, due to the training and guidance of several health professionals, researchers, and professors in the areas of nursing, medicine, and psychology, 13 systematic reviews have been published in the JBI Evidence Synthesis, being seven systematic reviews of effectiveness ${ }^{(18-24)}$, two reviews of reviews ${ }^{(25,26)}$, one systematic review of qualitative evidence ${ }^{(27)}$, one systematic review of prevalence and incidence ${ }^{(28)}$, and two scoping reviews ${ }^{(29,30)}$. Globally, these reviews address different themes of relevance to the field of nursing, as follows: active aging, differentiated nursing care methodologies (complex), wound care, transitions in health and self-care, and health education and literacy.

Ten reviews were also published in other journals by 2020 . In this case, four systematic reviews of effectiveness, a systematic review of prevalence and incidence, and five scoping reviews.

\section{DISCUSSION}

The CSRTP training allows the training of health professionals, researchers, and professors in the health area for the synthesis of science, notably by teaching how to carry out systematic reviews through the JBI approach. Moreover, this course facilitates the understanding and use of systematic reviews to inform clinical practice when providing healthcare.

For the trainers, some challenges are raised, such as: the constant updating of the existing review methodologies and the creation of new methodologies that require continuous update work from the trainers; the use of training materials developed by JBI and with annual improvements; and a training program with reduced time for teaching content and for discussion, which makes time management difficult. To overcome these challenges, each of the trainers has been specializing in a specific area, facilitating an in-depth study of contents and constant updating.

Regarding the impact of this type of training on research, teaching, and health care provision, it is expected that this training will promote the development of better quality systematic reviews and, consequently, allow the updating and integration of the best scientific knowledge, resulting in positive impact on health care and health education. However, so far, it has not been possible to study the effects of this course on the quality of teaching, research, and health outcomes. Despite this being a concern of the PCEBP, the fact that the participants come from different contexts makes this analysis more challenging.

\section{CONCLUSION}

The Portugal Center for Evidence-Based Practice is a fundamental resource of the Development Strategic Axis for the Synthesis and Implementation of Science and has been, since its beginning in 2011, strongly committed to the development of evidence synthesis, with the purpose of promoting informed health decision-making and, consequently, contributing to better health outcomes.

The center intends to continue to invest in the training and guidance of health professionals to encourage the use of evidence in health decision-making processes. Consequently, there is a plan to reinforce the team of trainers certified by the JBI for the CSRTP course in 2021.

Simultaneously, the Portugal Center for Evidence-Based Practice is, at this stage, developing the area of implementation of evidence, and, at this moment, the first course, accredited by the JBI, organized and taught by the center's staff, takes place.

\section{RESUMO}

Objetivo: Relatar a experiência do Portugal Centre For Evidence Based Practice (PCEBP): a JBI Centre of Excellence na formação de profissionais de saúde, pesquisadores e docentes no Comprehensive Systematic Review Training Program, um curso em Síntese da Evidência, especificamente sobre Revisões Sistemáticas da Literatura. Método: Este artigo tem como objetivo relatar a experiência do Portugal Centre For Evidence Based Practice: a JBI Centre of Excellence na implementação do Comprehensive Systematic Review Training Program que capacita profissionais de saúde, pesquisadores e docentes para o desenvolvimento de Revisões Sistemáticas, segundo a abordagem do JBI. Resultados: Até o final do ano 2020, foram desenvolvidas 11 edições do curso com um total de 136 participantes provenientes de diferentes instituições de ensino e de saúde, de diferentes países. Resultante da formação destes participantes, 13 revisões sistemáticas foram publicadas na JBI Evidence Synthesis e 10 revisões foram publicadas noutras revistas. Conclusão: Os referidos resultados e a avaliação de satisfação dos formados nos permitem realçar a pertinência do curso para a formação em síntese de evidência de profissionais de saúde. 


\section{DESCRITORES}

Prática Clínica Baseada em Evidências; Profissionais de Saúde; Cuidados de Saúde; Revisão Sistemática; Capacitação Profissional.

\section{RESUMEN}

Objetivo: Relatar la experiencia del Portugal Centre For Evidence Based Practice (PCEBP): a JBI Centre of Excellence en la formación de profesionales de salud, investigadores y docentes en el Comprehensive Systematic Review Training Program, un curso en Síntesis de la Evidencia, específicamente sobre Revisiones Sistemáticas de la Literatura. Método: Este artículo tiene como objetivo relatar la experiencia del Portugal Centre For Evidence Based Practice: a JBI Centre of Excellence en la implementación del Comprehensive Systematic Review Training Program que capacita profesionales de salud, investigadores y docentes para el desarrollo de Revisiones Sistemáticas, según la metodología del JBI. Resultados: Hasta el final del año 2020, fueron desarrolladas 11 ediciones del curso sumando en total 136 participantes provenientes de diferentes instituciones de enseñanza y de salud, de distintos países. Resultó tras la formación de estos participantes que, 13 revisiones sistemáticas fueron publicadas en la JBI Evidence Synthesis y 10 revisiones fueron publicadas en otras revistas. Conclusión: Los referidos resultados y la evaluación de satisfacción de los egresos nos permiten resaltar la pertinencia del curso para la formación en síntesis de evidencia de profesionales de salud.

\section{DESCRIPTORES}

Práctica Clínica Basada en la Evidencia; Personal de Salud; Atención a la Salud; Revisión Sistemática; Capacitación Profesional.

\section{REFERENCES}

1. Melnyk BM, Newhouse R. Evidence-based practice versus evidence-informed practice: a debate that could stall forward momentum in improving healthcare quality, safety, patient outcomes, and costs. Worldviews Evid Based Nurs. 2014;11(6):347-49. DOI: https://doi.org/10.1111/wvn.12070

2. Nevo I, Slonim-Nevo V. The myth of evidence-based practice: towards evidence-informed practice. Br J Soc Work. 2011;41(6):1176-97. DOI: https://doi.org/10.1093/bjsw/bcq149

3. Pearson A, Wiechula R, Court A, Lockwood C. The JBI model of evidence-based healthcare. Int J Evid Based Healthc. 2005;3(8):207-15. DOI: https://doi.org/10.1111/j.1479-6988.2005.00026.x

4. Melnyk BM, Gallagher-Ford L, Long LE, Fineout-Overholt E. The establishment of evidence-based practice competencies for practicing registered nurses and advanced practice nurses in real-world clinical settings: proficiencies to improve healthcare quality, reliability, patient outcomes, and costs. Worldviews Evid Based Nurs. 2014;11(1):5-15. DOI: https://doi.org/10.1111/wvn.12021

5. Jordan Z, Lockwood C, Munn Z, Aromataris E. The updated Joanna Briggs Institute Model of Evidence-Based Healthcare. Int J Evid Based Healthc. 2019;17(1):58-71. DOI: https://doi.org/10.1097/xeb.0000000000000155

6. Dawes M, Summerskill W, Glasziou P, Cartabellotta A, Martin J, Hopayian K, et al. Sicily statement on evidence-based practice. BMC Med Educ. 2005;5:1. DOI: https://doi.org/10.1186/1472-6920-5-1

7. White KM, Dudley-Brown S. Translation of Evidence into Practice: Application to Nursing and Health Care. New York: Springer; 2012.

8. Greenhalgh T. How to implement evidence-based healthcare. Oxford: John Wiley \& Sons; 2018.

9. Bastian H, Glasziou P, Chalmers, I. Seventy-five trials and eleven systematic reviews a day: how will we ever keep up? PLoS Med. 2010;7(9):e1000326. DOI: https://doi.org/10.1371/journal.pmed.1000326

10. National Library of Medicine [Internet]. Detailed Indexing Statistics: 1965-2017 [cited 2021 Jan]. Bethesda: NLA;2018. Available from: https:// wayback.archive-it.org/org-350/20200416174438/https://www.nlm.nih.gov/bsd/index_stats_comp.html

11. JBI Manual for Evidence Synthesis [Internet]. Adelaide: JBI;2020 [cited 2021 Jan 15]. Available from: https://synthesismanual.jbi.global

12. Institute of Medicine (US) Committee on Standards for Developing Trustworthy Clinical Practice Guidelines; Graham R, Mancher M, Miller Wolman D, Greenfield, S. Steinberg, E. Clinical Practice Guidelines We Can Trust [Internet]. Washington (DC): National Academies Press. 2011 [cited 2021 Jan 17]. Available from: https://www.ncbi.nlm.nih.gov/books/NBK209539/

13. JBI Global Wiki [Internet]. Adelaide: JBI;2019 [cited 2021 Jan 20]. Available from: https://wiki.jbi.global/pages/viewpage.action?pageld=18055242

14. JBI Collaboration. Handbook 2021 [Internet]. Adelaide: The University of Adelaide;2021 [cited 2021 Jan 20 ]. Available from: https://jbi-global-wiki. refined.site/space/JBCI/1147895565/General+JBI\%2FJBIC+Resources?attachment=/download/attachments/1147895565/JBIC\%20Handbook\%20 2021.pdf\&type=application/pdf

15. Rodrigues MA. Modelo Cross-cutting para gestão de atividades I\&D e inovação: no caminho da moderna investigação em enfermagem. Revista de Enfermagem Referência. 2018;(18):141-54. DOI: https://doi.org/10.12707/RIV18000

16. Stern C, Munn Z, Porritt K, Lockwood C, Peters MD, Bellman S, et al. (2018). An international educational training course for conducting systematic reviews in health care: the Joanna Briggs Institute's comprehensive systematic review training program. Worldviews Evid Based Nurs. 2018;15(5):401-08. DOI: https://doi.org/10.1111/wvn.12314

17. Aromataris E, Pearson A. The systematic review: an overview. Am J Nurs. 2014;114(3):53-8. DOI: https://doi.org/10.1097/01.NAJ. $0000444496.24228 .2 \mathrm{C}$

18. Apóstolo J, Queirós P, Rodrigues M, Castro I, Cardoso D. The effectiveness of nonpharmacological interventions in older adults with depressive disorders: a systematic review. JBI Database System Rev Implement Rep. 2015;13(6):220-78. DOI: https://doi.org/10.11124/jbisrir-2015-1718

19. Apóstolo J, Cooke R, Bobrowicz-Campos E, Santana S, Marcucci M, Cano A, et al. Effectiveness of interventions to prevent pre-frailty and frailty progression in older adults: a systematic review. JBI Database System Rev Implement Rep. 2018;16(1):140. DOI: https://doi.org/10.11124/ JBISRIR-2017-003382

20. Marques P, Queirós C, Apóstolo J, Cardoso D. Effectiveness of bedrails in preventing falls among hospitalized older adults: a systematic review. JBI Database System Rev Implement Rep. 2017;15(10):2527-54. DOI: https://doi.org/10.11124/jbisrir-2017-003362

21. Queirós P, Santos E, Apóstolo J, Cardoso D, Cunha M, Rodrigues, M. The effectiveness of cleansing solutions for wound treatment: A systematic review. JBI Database System Rev Implement Rep. 2014;12(10):121-51. DOI: https://doi.org/10.11124/jbisrir-2014-1746 
22. Santos E, Cardoso D, Apóstolo J, Neves H, Cunha M, Rodrigues M. Effectiveness of haloperidol prophylaxis in critically ill patients with a high risk of delirium: a systematic review. JBI Database System Rev Implement Rep. 2017;15(5):1440-72. DOI: https://doi.org/10.11124/ JBISRIR-2017-003391

23. Silva R, Abrunheiro S, Cardoso D, Costa P, Couto F, Agrenha, C, et al. Effectiveness of multisensory stimulation in managing neuropsychiatric symptoms in older adults with major neurocognitive disorder: a systematic review. JBI Database System Rev Implement Rep. 2018;16(8): 1663-708. DOI: https://doi.org/10.11124/JBISRIR-2017-003483

24. Silva R, Bobrowicz-Campos E, Cardoso D, Costa P, Couto F, Camarneiro AP, et al. Effects of caregiver-provided individual cognitive interventions on cognition, social functioning and quality of life in older adults with major neurocognitive disorders: a systematic review. JBI Evid Synth. 2020;18(4):743-806. DOI: https://doi.org/10.11124/JBISRIR-D-19-00125

25. Apóstolo J, Cooke R, Bobrowicz-Campos E, Santana S, Marcucci M, Cano A, et al. Predicting risk and outcomes for frail older adults: an umbrella review of frailty screening tools. JBI Database System Rev Implement Rep. 2017;15(4):1154-208. DOI: https://doi.org/10.11124/ JBISRIR-2016-003018

26. Santos EJF, Duarte C, Marques A, Cardoso D, Apóstolo J, Silva JAP, et al. Effectiveness of non-pharmacological and non-surgical interventions for rheumatoid arthritis: an umbrella review. JBI Database System Rev Implement Rep. 2019;17(7):1494-531. DOI: https://doi.org/10.11124/ jbisrir-d-18-00020

27. Loureiro H, Mendes A, Rodrigues R, Apóstolo J, Rodrigues M, Cardoso D, et al. The experience of programs to promote health in retirement: a systematic review of qualitative evidence. JBI Database System Rev Implement Rep. 2015;13(4):276-94. DOI: https://doi.org/10.11124/ jbisrir-2015-1754

28. Parola V, Coelho A, Cardoso D, Gea-Sanchez M, Blanco-Blanco J, Apóstolo J. The prevalence of burnout in health professionals working in palliative care: a systematic review. JBI Database System Rev Implement Rep. 2017;15(7). DOI: https://doi.org/10.11124/JBISRIR-2016-003309

29. Coelho A, Parola V, Cardoso D, Escobar M, Apóstolo J. The use of non-pharmacological interventions for the comfort of patients in palliative care: a scoping review. JBI Database System Rev Implement Rep. 2017;15(7):1867-904. DOI: https://doi.org/10.11124/JBISRIR-2016-003204

30. Silva RS, Caldeira S, Coelho AN, Apóstolo JLA. Forgiveness facilitation in palliative care: a scoping review. JBI Evid Synth. 2020;18(11):2196-230. DOI: https://doi.org/10.11124/JBISRIR-D-19-00286

\section{Financial support}

Fundação para a Ciência e Tecnologia (FCT), I.P., Project Ref. UIDP/00742/2020. 